\title{
Ectopic pleomorphic adenoma on subcutaneous plane of the cheek
}

\author{
Yong Hun Kim, \\ Hyung Woo Yoon, \\ Jiye Kim, \\ Sug Won Kim \\ Department of Plastic and \\ Reconstructive Surgery, Wonju \\ Severance Christian Hospital, Yonsei \\ University Wonju College of Medicine, \\ Wonju, Korea
}

Pleomorphic adenoma is the most common benign tumor of the salivary gland. Pleomorphic adenoma occurs most commonly in the parotid gland but it may involve other salivary gland such as submandible or lingual. We report an ectopic pleomorphic adenoma in the subcutaneous layer of the face. A woman presented with a mass of the nasolabial fold. After excision of the mass, it was revealed as an pleomorphic adenoma pathologically. An ectopic pleomorphic adenoma which was located in the subcutaneous layer of the face is very rare in medical literature.

Keywords: Adenoma / Parotid neoplasms / Pleomorphic adenoma / Salivary gland neoplasms / Skin / Subcutaneous tissue

\section{INTRODUCTION}

Pleomorphic adenoma, the most common tumor of the salivary gland, consists of epithelial and mesenchymal components. It is a benign neoplasm which is commonly encountered in the parotid gland and other major salivary glands. At times they can also develop in minor salivary glands of the palate. We present an unsuspected case of an ectopic pleomorphic adenoma on the nasolabial fold which was found in subcutaneous plane.

\section{CASE REPORT}

A 43-year-old married woman visited the department of plastic and reconstructive surgery with a chief complaint of a mass in the nasolabial fold that had grown increasingly since last 3 months. On physical examination, $1 \times 1$-cm-sized soft and palpable, painless mass was observed on the left nasolabial fold of the patient. The lady had no other complaint except palpable

\footnotetext{
Correspondence: Sug Won Kim

Department of Plastic and Reconstructive Surgery, Wonju Severance Christian

Hospital, Yonsei University Wonju College of Medicine, 20 Ilsan-ro, Wonju 26426,

Korea

E-mail: sugwonkim@yonsei.ac.kr

Received June 18, 2018 / Revised October 15, 2018 / Accepted October 16, 2018
}

mass of her face. There was no history of systemic fever, localized heat, any other type of discharge from mass lesion. On the past history of the patient, there was no history of similar lesion and neither was significant medical or surgical illness. The patient presented for the first time for above complaint in our hospital. General appearance of the patient was well-being. General examination revealed normal and stable vital sign. The laboratory examination including common blood cell, chemistries were within normal limits. On physical examination there was a round mass on left side of nasolabial fold with about $1 \times$ 1-cm-sized, round shape, firm, and well-defined margins. As followed examination, it was similar to some benign soft tissue mass such as epidermal cyst or pilomatricoma. The patient was then advised surgical removal of the mass. Preoperative blood and urine tests were performed within normal range. The patient underwent surgery under local anesthesia using 1:100,000 diluted epinephrine mixed lidocaine. Incision line was designed parallel to relaxed skin tension line for minimalization of postoperative scarring. A mass was revealed on layer of subcutaneous soft tissue. It was well defined from around normal soft tissues. Complete excision was successfully done and surgical wound was closed with primary repair. Excised mass was showed $0.7 \times 0.4 \times 0.3 \mathrm{~cm}$, firm and rubbery (Fig. 1). Histopath- 

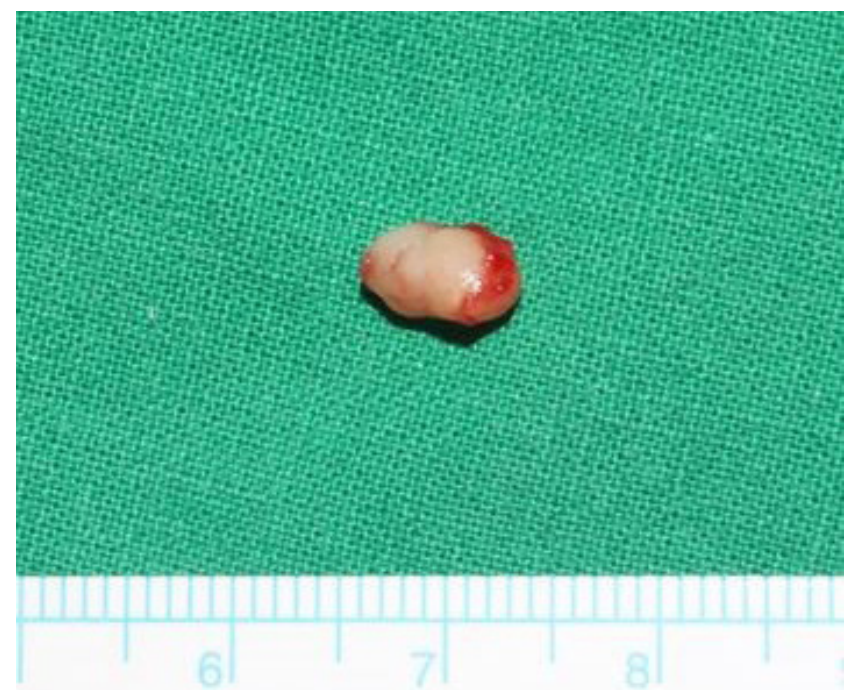

Fig. 1. Gross inspection of ectopic pleomorphic adenoma. It showed soft, firm, and rubbery characteristics.

ological examination revealed a pleomorphic adenoma which contains mixed epithelial and myoepithelial cells with duct-like structures (Fig. 2).

\section{DISCUSSION}

Pleomorphic adenomas are the most common benign salivary gland neoplasm. It accounts for $60 \%-70 \%$ of all parotid neoplasias, $40 \%-60 \%$ of all submandibular neoplasias, and $40 \%-70 \%$ of minor salivary gland neoplasias [1].

Majority of minor salivary glands are present in hard palate, buccal mucosa, and upper and lower lip. Other sites are floor of the mouth, inferior surface of the tongue, palatoglossal folds, and tonsillar region. Mostly it occurs between fourth and sixth decade of age, with male to female ratio varying from 1:1.4 to 1:1.7 [2]. Clinical presentation includes asymptomatic, slow growing firm mass. Small tumors typically form smooth, mobile, firm lumps but larger tumors tend to become bossellated and may attenuate the overlying skin or mucosa [3]. In our case, an ectopic pleomorphic adenoma appeared painless, soft character, it showed a clinical presentation similar to benign soft tissue tumors such as epidermal cyst and pilomatricoma. Pleomorphic adenoma ectopically presents in the soft tissue of the neck, lymph nodes, tongue, mandible, hypophysis, mastoid bone, thyroid, parathyroid, subcutaneous layer of the nose, and skin of the external auditory canal [4]. Willis [5] proposed three main hypotheses to explain this kind of heterotopias. These were an abnormal persistence and development of vestigial structures, dislocation of portion of a deficient rudiment during mass movement and development, and abnormal differentia-
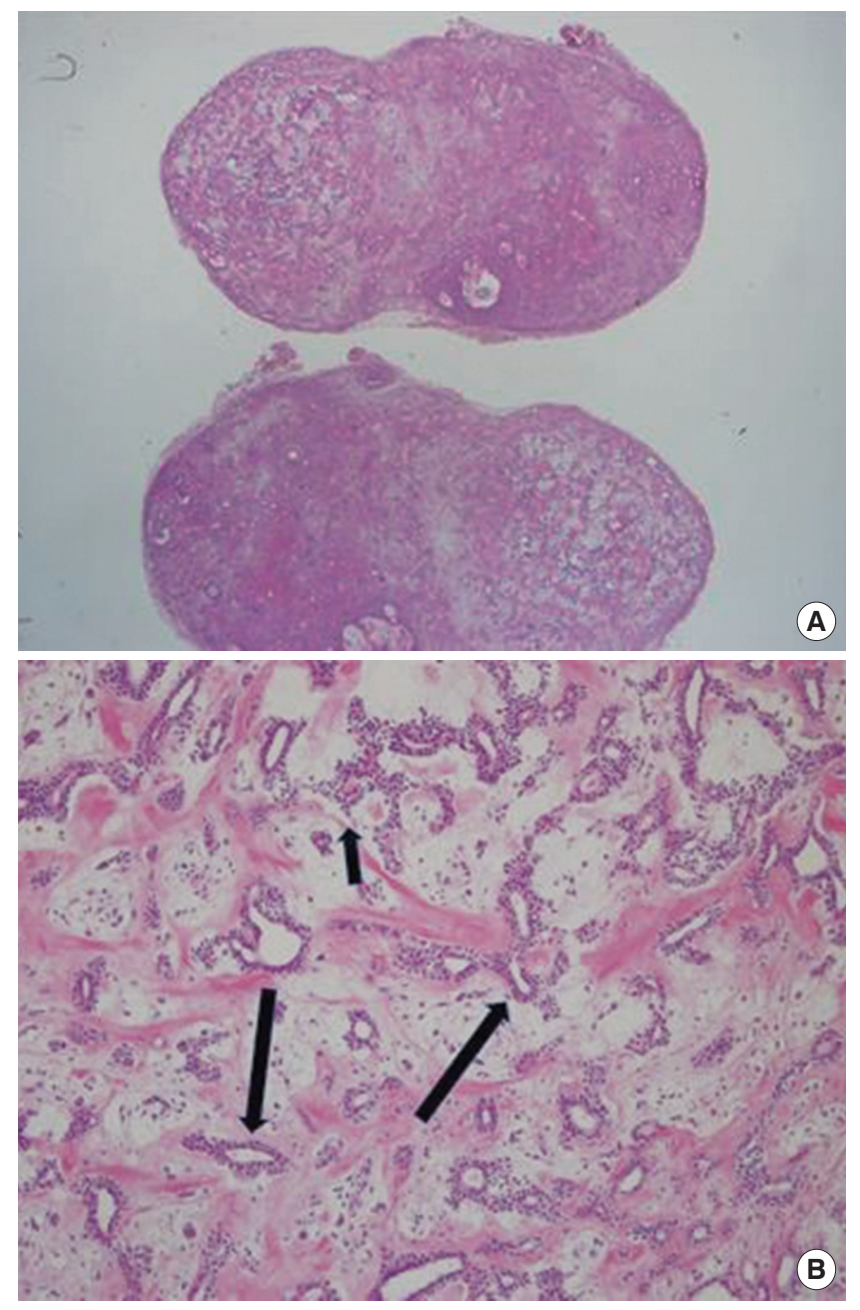

Fig. 2. (A) Histopathological examination, cross-sectional inspection of a mass $(\mathrm{H} \& \mathrm{E}, \times 10)$. (B) Pleomorphic adenoma which contains epithelial cells (short arrow) and myoepithelial cells with duct-like gland components (long arrows) $(\mathrm{H} \& \mathrm{E}, \times 20)$.

tion of the local tissues (heteroplasia). This may happen due to metaplasia, neoplastic degeneration of ectopic salivary gland tissue or due to the implantation after surgical excision of the salivary gland tumor [6]. Pleomorphic adenoma in $5 \%$ of cases can undergo malignant transformation into carcinoma ex pleomorphic adenoma and metastasizing benign mixed tumor. Radiotherapy is not indicated due to the radioresistant behavior of the tumor. Prognosis is excellent (95\%) after complete excision [7]. Thus ectopic appearance of the pleomorphic adenoma in an unusual location can lead to a diagnostic dilemma to the surgeons and a pathological confirmation is indispensable.

Pleomorphic adenoma is a benign tumor that mainly occurs in the salivary gland. However, as in this case, a tumor that develops in the facial region needs to be differential diagnosis through a pathologic confirmation. 


\section{NOTES}

\section{Conflict of interest}

No potential conflict of interest relevant to this article was reported.

\section{Ethical approval}

The study was performed in accordance with the principles of the Declaration of Helsinki. Written informed consent was obtained.

\section{ORCID}

Yong Hun Kim https://orcid.org/0000-0002-6092-4374

Hyung Woo Yoon https://orcid.org/0000-0002-0216-1700

Jiye Kim https://orcid.org/0000-0002-1724-4250

Sug Won Kim https://orcid.org/0000-0002-2354-7100

\section{REFERENCES}

1. Ellis GL, Auclair PL, Gnepp DR. Surgical pathology of salivary gland. Philadelphia: WB Saunders; 1991.

2. van Heerden WF, Raubenheimer EJ. Intraoral salivary gland neoplasms: a retrospective study of seventy cases in an African population. Oral Surg Oral Med Oral Pathol 1991;71:579-82.

3. Rajendran S, Sivapathasundharam B. Shafer's textbook of oral pathology. 6th ed. New Delhi: Elsevier; 2009.

4. Chung JH, Burm JS, Oh SJ. An ectopic pleomorphic adenoma in the superficial subcutaneous layer of the preauricular area. J Korean Soc Plast Reconstr Surg 2002;29:115-7.

5. Willis RA. Some unusual developmental heterotopias. Br Med J 1968;3:267-72.

6. Tsukuno M, Nakamura A, Takai S, Kurihara K. Subcutaneous pleomorphic adenomas in two different areas of the face. Scand J Plast Reconstr Surg Hand Surg 2002;36:109-11.

7. Neville BW, Damm DD, Allen CM, Bouquot JE. Oral and maxillofacial pathology. 3rd ed. St. Louis: Saunders Elsevier; 2009. 